\title{
A Study of R. C. C. Beam Column Junction Subjected To Quasi- Static (Monotonic) loading
}

\author{
S. S. Patil, C. G. Konapure \& S. S. Manekari \\ ( Civil Egg. Depts. W. I. T. Solapur University, India)( Civil Egg. Depts. W. I. T. Solapur University, India) \\ ( Civil Egg. Depts. W. I. T. Solapur University, India)
}

\begin{abstract}
Beam and column where intersects is called as joint or junction. The different types of joints are classified as corner joint, exterior joint, interior joint etc. on beam column joint applying quasi-static loading on cantilever end of the beam. and study of various parameters as to be find out on corner and exterior beam column joint i.e. maximum stress, minimum stress, displacement and variation in stiffness of beam column joint can be analyzed in Ansys software (Non-Linear FEM Software) Significant experimental research has been conducted over the past three decades on hysteretic behavior of beam-column joints of RC frames under cyclic displacement loading. The various research studies focused on corner and exterior beam column joints and their behavior, support conditions of beam-column joints. Some recent experimental studies, however, addressed beam-column joints of substandard RC frames with weak columns, poor anchorage of longitudinal beam bars and insufficient transverse reinforcement. the behavior of exterior beam column joint is different than the corner beam column joint.
\end{abstract}

Keywords- beam, column, corner, exterior, joint, quasi-static.

\section{Introduction}

Design and detailing of beam-column joints in reinforced concrete frames are critical in assuring the safety of these structures in earthquakes. Such joints should be designed and detailed to Preserve the integrity of the joints sufficiently to develop the ultimate strength and deformation capacities of the connecting beams and columns; Prevent excessive degradation of joint stiffness under seismic loading by minimizing cracking of the joint concrete and by preventing the loss of bond between the concrete and longitudinal beam and column reinforcement; and Prevent brittle shear failure of the joint It has recently been reported that the beam column joints. failures observed in 1980 Assam earthquake, 1985 Mexico, 1986 Salvador, 1989 Loma Prieta and 2000 in India. It is recognizing that Beam-Column Joints can be critical reason in RC frames design for in elastic response to severe seismic attack. As a consequence, seismic moments of opposite signs are develop in columns above and below the joints and at the same time beam moment reversal across the joints. A horizontal and vertical shear force whose magnitude is many times higher than in the adjacent beams and columns developed at the joint region. If not design for, joint failure can result.

\section{Literature Review}

The strength of beam-column junction plays a very important role in the strength of the structure, here the literature survey is carried out to have the information about the Quasi-static Loading applied to the beamcolumn joint.

Hegger Josef,Sherif Alaa and Roeser Wolfgang ${ }^{[8]}$ this paper investigate the behavior of exterior and interior beam-column joints by Nonlinear finite element analysis using ATENA a software for nonlinear analysis of reinforced concrete structures. The model has been calibrated using the results of the third author's tests. The behavior of exterior and interior beam-column turned out to be different .The parameters influencing the shear strength are not the same for both types of connections. Different parameters like effect of the material properties, effect of geometry of connection, effect of reinforcement, effect of concrete compressive strength and joint slenderness. The parameters influencing the shear capacity are different for exterior and interior connections. The FE results were compared with the author's experimental results and the good agreement between the two was achieved.

Kuang J.S. and Wong H. F. ${ }^{[2]}$ Reversed cyclic-load tests are carried out on full-scale reinforced concrete (RC) exterior beam-column joints, which are fabricated to simulate those in as-built RC framed buildings designed to BS 8110. Emphasis of the study is placed on the effects of the types of beam bar anchorage and location of laps in column reinforcement on the seismic behavior and shear strength of RC exterior joints subjected to simulated earthquake load. Shear strength of a beam-column joint predicted by the criterion of initial diagonal cracking is highly dependent on the level of axial loads applied on the column; this model gives very good correlations with all the test data in this study 
Ha G.J and Cho .C.G ${ }^{[12]}$ Lack of ductility in high-strength concrete members raises serious concerns for overall structural safety, especially for reinforced concrete beam-column joints. In the current study, experimental research was performed to improve the seismic strength and performance of reinforced highstrength concrete exterior beam-column joints under cyclic load reversals. A new design approach for beamcolumn joints was introduced using advanced reinforcement details. Specimens of reinforced high-strength concrete beam-column joints were manufactured based on the new design method developed from the concept of a moving beam plastic hinge using anchor-type intermediate bars and advanced details of doubly confined closed stirrups in the beam near the joint, and tested for comparison with specimens designed using the conventional approach. The newly developed design approach minimized damage and considerably improved the structural performance of beam-column joints under cyclic load reversals. The manufactured joints were expected to be effective in improving the weakness in induced by the brittleness of high-strength concrete in reinforced high-strength concrete beam-column joints.

Bing Li, Yiming Wu, and Tso-Chien Pan ${ }^{[4]}$ described the development of finite element model for interior beam-wide column joints. The global behavior and the principal stresses of the interior beam-wide column joints discussed in detail and the results are compared with the author's experimental results. The calculated results indicated the global behavior of the joint simulated to correlate and well within the experimental observations. The effects of several critical design parameters on the joint behavior are explored by means of finite element models

\section{Framed Connections}

Beam column joints can be critical regions in reinforced concrete frames designed for inelastic response to severe seismic attack. The reversal in moment across the joint also means that the beam reinforcement is required to be in compression on one side of the joint and at tensile yield on the other side of the joint. The high bond stress required to sustain this force gradient across the joint may cause bond failure and corresponding degradation of moment capacity accompanied by excessive drift. In the analysis of reinforced concrete moment resisting frames the joints are generally assumed as rigid. In Indian practice, the joint is usually neglected for specific design with attention being restricted to provision of sufficient anchorage for beam longitudinal reinforcement. This may be acceptable when the frame is not subjected to earthquake loads. There have been many catastrophic failures reported in the past earthquakes, in particular with Turkey and Taiwan earthquakes occurred in 1999, which have been attributed to beam-column joints. The poor design practice of beam column joints is compounded by the high demand imposed by the adjoining flexural members (beams and columns) in the event of mobilizing their inelastic capacities to dissipate seismic energy. Unsafe design and detailing within the joint region jeopardizes the entire structure, even if other structural members conform to the design requirements. Since past three decades extensive research has been carried out on studying the behavior of joints under seismic conditions through experimental and analytical studies. Various international codes of practices have been undergoing periodic revisions to incorporate the research findings into practice. The paper is aimed at making designers aware of the theoretical background on the design of beam column joints highlighting important parameters affecting seismic behavior of joints.

\subsection{Criteria for the desirable performance of joints in ductile structures designed for earthquake resistance:}

1. The strength of the joint should not be less than the maximum demand corresponding to development of the structural plastic hinge mechanism for the frame. This will eliminate the need for repair in a relatively inaccessible region and for energy dissipation by joint mechanisms, which as will be seen subsequently, undergo serious stiffness and strength degradation when subjected to cyclic actions in the inelastic range.

2. The Capacity of the column should not be jeopardized by possible strength degradation within the joint. The joint should also be considered as an integral part of the column.

3. During moderate seismic disturbances, joints should preferably respond within the range.

4. Joint deformations should not significantly increase story drift.

5. The joint reinforcement necessary to ensure satisfactory performance should not cause undue construction difficulties.

3.2 Performance Criteria: Because the response of joints is controlled by shear and bond mechanisms, both of which exhibit poor hysteric properties, joints should be regarded as being unsuitable as major sources of energy dissipation. Hence the response of joints should be restricted essentially to the elastic domain. It is of particular importance to ensure that joint deformations, associated with shear and particularly bond mechanisms, do not contribute excessively to overall story drifts. When large diameter beam bars are used, the early break down of the bond within the joint may lead to story drifts in excess of $1 \%$, even before the yield strength of such bars is attained in adjacent beams. Excessive drifts may cause significant damage to non structural components 
of the building, while frames respond within the elastic domain. By appropriate detailing, to be examined subsequently, joint deformations can be controlled.

\subsection{SHEAR STRENGTH}

Internal forces transmitted from adjacent members to the joint as shown in fig. result in joint shear forces in both the horizontal and vertical directions. These shear forces lead to diagonal compression and tension stresses in the joint core. The latter will usually result in diagonal cracking of the concrete core. The mechanism of shear resistance at this stage changes drastically.

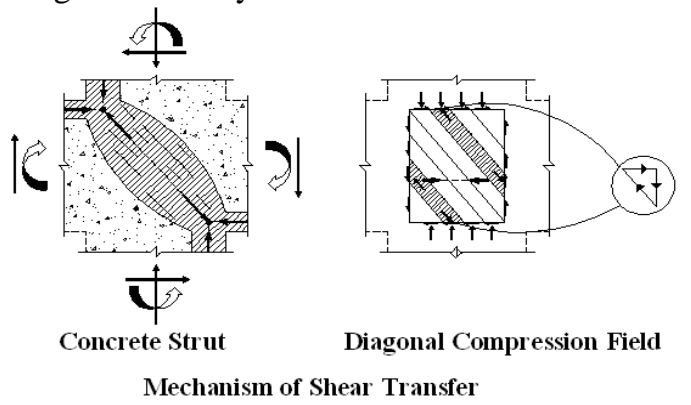

Fig.1 Shear Mechanism

Some of the internal forces, particularly those generated in the concrete, will combine to develop a diagonal strut. Other forces, transmitted to the joint core form beam and column by means of bond, necessitate a truss mechanism.

To prevent shear failure by diagonal tension, usually along a potential corner to corner failure plane. Both the horizontal and vertical shear reinforcement will be required. Such reinforcement will enable a diagonal compression field to be mobilized, which provides a feasible load path for both horizontal and vertical shear forces. The amount of horizontal joint shear reinforcement required, may be significantly more than would normally be provided in columns in the form of ties or hoops, particularly when axial compression on columns is small.

When the joint shear reinforcement is sufficient, yielding of the hoops will occur. Irrespective of the direction of diagonal cracking, horizontal shear reinforcement transmits tension forces only. The inelastic steel strains that may result are irreversible. Consequently, during subsequent loading, stirrup ties can make a significant contribution to shear resistance only if the tensile strains imposed are larger then those developed previously. This then leads to drastic loss of stiffness art low shear force levels, particularly immediately after a force or displacement reversal.

\subsection{BOND STRENGTH}

At exterior column the difficulty in anchoring a beam bear of full strength can be overcome readily by providing a standard hook. At interior columns, however, this is impractical. Some codes require that beam bars at interior beam-column joints must pass continuously that bars may be anchored with equal if not greater efficiency using standard hooks within or immediately behind an interior joint.

The fact that bars passing through interior joints are being "pulled" as well "pushed" by the adjacent beams, to transmit forces corresponding to steel stresses up to the strain hardening range in tension, has not as a rule, been take into account code specifications until recently. In most practical situations bond stresses required to transmit bar forces to the concrete of the joint core consistent with plastic hinge development at both sides of the joint, would be very large and well beyond limits considered by codes for bar strength development. Even at moderate ductility demands, a slip of beam bars through the joint can occur. A breakdown of bond within interior joints does not necessarily result in sudden loss of strength.

\subsection{DESIGN OF JOINTS}

\section{Joint types}

According to geometrical configuration

I) Interior

II) Exterior

II) Corner

According to loading conditions and structural behavior

I) Type-I

II) Type-II 
Type1- Static loading

I) Strength important

II) Ductility secondary

A type-1 joint connects members in an ordinary structure designed on the basis of strength, to resist the gravity and

wind load.

Type2-earthquake and blast loading

I) Ductility + strength

II) Inelastic range of deformation

III) Stress reversal

A type-2 joint connects members designed to have sustained strength under deformation reversals into the inelastic range, such as members designed for earthquake motions, very high wind loads, or blast effects.

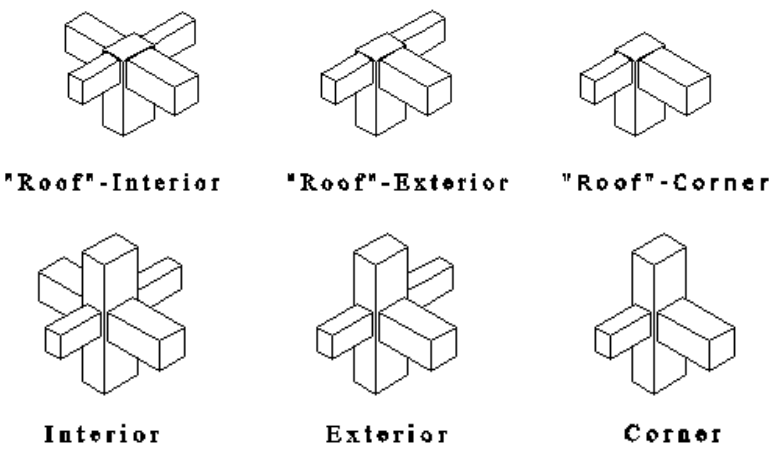

Fig. 2 Typical Beam Column Connections

3.6 The design procedure of beam-column joints consists of the following steps:

1. Arrive at the preliminary size for members based on anchorage requirements for the chosen longitudinal bars.

2. Ensure adequate flexural strength of columns to get the desired beam yielding mechanism.

3. Arrive at the design shear force for the joint by evaluating the flexural over strength of the adjacent beams and corresponding internal forces. The simultaneous forces in the column that maintain joint equilibrium must also be determined. From these, the joint shear force demand can be calculated.

4. Obtain effective joint shear area from the adjoining member dimensions.

5. Ensure that the induced shear stress is less than the allowable stress limit. The allowable shear stress limit is expressed as a function of the compressive strength or diagonal tensile strength of concrete. If not satisfied, alter the associated member dimensions, viz., width of the beam or depth of the column.

6. Provide transverse reinforcements both as confining reinforcement and as shear reinforcement.

7. Provide sufficient anchorage for the reinforcement passing through or terminating in the joint.

\section{Loading Systems}

The structures are being imposed by many loads e.g. dead load, live load, imposed(wind) load, snow load, earthquake load etc. The structures have to be designed in such a way that they can bear these loads to overcome the collapse or failure of the structures.

\subsection{Types of Loading systems:-}

The behavior of building is studied with different types of loads.

Static loading :- Static means slow loading in structural testing. Test of components:-Beams(bending),column (axial),beams and columns

Purpose of testing:- Determine strength limits

Determine the flexibility/rigidity of structures

Quasi-static loading:- Very slowly applied loading in one direction (monotonic)

Quasi-static reversed cyclic loading:-Very slowly applied loading in both direction (cyclic)

Dynamic (random) loading:- Shake at the base or any other elevation of the structure shaking similar to that during earthquakes.

As a rule cyclic loading is applied under displacement-control, with cycles of gradually increasing amplitude. For large-scale specimen's actuator stroke length limitations do not allow the ultimate deformation of the 
specimen to be reached under monotonic loading. The monotonic shear resistance should be significantly higher than the flexure one, because under cyclic conditions shear strength and stiffness deteriorate much faster than the flexural, so shear deformations may become dominant with cycling and failure may takes place at interesting inclined cracks.

Cycling causes a degradation of strength with respect to the envelope provided by the virgin loading curves. This strength degradation is more evident between one cycle of deformation and the next, at the same level of peak deformation

\section{Finite Element Method}

The basic concept in this method is that a body or a structure may be divided into smaller elements of finite dimensions called 'Finite Elements'. The original body or the structure is then considered as an assemblage of these elements connected at a finite number of joints called 'Nodes' or 'Nodal Points'. The properties of the elements are formulated and combined to obtain the solution for the entire body or structure. The finite element procedure reduced the unknown infinite numbers by dividing into small elements and by expressing the unknown field variables in terms of assumed approximating functions such as shape functions.

1. Selection of field variables and the elements.

2. Discretization of structure.

3. Finding the element properties

4. Assembling element stiffness matrix

5. Solution of nodal unknown

\subsection{DISCRETIZATION OF STRUCTURE}

The process of modeling a structure using suitable number, shape and size of the elements is called Discretization. Modeling should be good enough to get results as close to actual behavior of the structure as possible.

\subsection{NODAL LOADS}

While subdividing a structure, nodal locations are selected so as to coincide with external loads applied. This can be easily done in case of concentrated load. But in case of distributed loads like self weight, uniformly distributed load, uniformly varying load, a technique of transferring the loads as nodal loads is adopted. In transferring the load, a portion is assigned to each node and load on that region is considered as nodal load.

\subsection{ASSEMBLY AND SOLUTION OF EQUATIONS}

In assembling the element stiffness equation, $[\mathrm{K}]\{\delta\}=\{\mathrm{F}\}$, the first step is to derive the expression for element stiffness property and nodal force vector. The overall stiffness matrix and nodal load vectors are assembled from elements and then the set of simultaneous equations are solved to obtain the nodal displacements. Then the nodal stresses are obtained from the stress displacement relations.

\subsection{FINITE ELEMENT MODELING \& ANALYSIS:}

Ansys software has been used for conducting the finite element analysis of the Concrete Beam Column Joint. Ansys has many features which help to carry out detailed study for such kind of complex problems.

\section{Problem Definition}

\section{Problem Statement}

- A G+5 RCC Commercial building is considered.

- Plan dimensions :12 m x $12 \mathrm{~m}$

- $\quad$ Location considered: Zone-IV

- $\quad$ Soil Type considered: Hard Strata.

General Data of Building:

- Grade of concrete : M 25

- Grade of steel considered : Fe 250, Fe 500

- Live load on roof: $2 \mathrm{KN} / \mathrm{m}^{2}$ (Nil for earthquake)

- Live load on floors : $4 \mathrm{KN} / \mathrm{m}^{2}$

- Roof finish : $1.0 \mathrm{KN} / \mathrm{m}^{2}$

- Floor finish : $1.0 \mathrm{KN} / \mathrm{m}^{2}$

- Brick wall in longitudinal direction : $240 \mathrm{~mm}$ thick

- Brick wall in transverse direction : $140 \mathrm{~mm}$ thick

- Beam in longitudinal direction : $230 \times 350 \mathrm{~mm}$ 
- Beam in transverse direction : $230 \times 350 \mathrm{~mm}$

- Column size : $300 \times 750 \mathrm{~mm}$

- Density of concrete : $25 \mathrm{KN} / \mathrm{m}^{3}$

- Density of brick wall including plaster : $20 \mathrm{KN} / \mathrm{m}^{3}$

- Plinth beam(PB1) : $350 \times 270 \mathrm{~mm}$

- Plinth beam(PB2) : $270 \times 300 \mathrm{~mm}$

-

6.1 Analysis :-

1) Ansys Software

( Non-Linear finite element

analysis ) :The exterior and corner beam-column joint to be analyzed in the Ansys FEM Software.

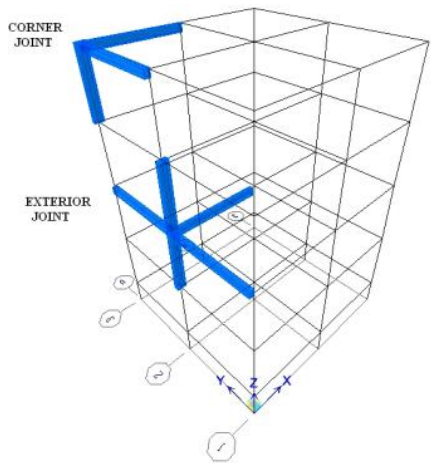

Fig.3 Dimensional view showing exterior and corner beam-column joint

\section{2) Ansys Analysis:}

Once the reinforcement detailing of the beam and column is known the exterior beam-column joint is modeled in Ansys FEM Software. Non-linear analysis of exterior and corner joint is carried out with 6 load step and 30 iterations in each load step. The mesh size of $80 \mathrm{~mm}$ is taken for macro-elements in concrete part of the beam and column. The exterior beam-column joint is modeled and a monotonic loading of $5 \mathrm{KN}$ is applied at the tip of the beam till the failure of the beam takes place. The application of the monotonic loading is shown in fig.6.4.The behavior of this joint is studied with different parameters.

VII. $\quad$ Finite Element Modeling And Analysis Of Beam-Column Joints:

The exterior and corner beam-column joint is considered to study joint behavior subjected to monotonic loading. Preparation of FE model is carried out based on results obtained from space frame analysis of a building located in zone-IV. Model construction is done by defining geometrical joints and lines. Material definition is carried out prior to assigning of macro elements. The joint is fully restrained at the column ends. The load is applied at the tip of the beam in one direction.

Mesh arrangement:- A single mesh arrangement was developed for use with the bent down bar anchorage.

\subsection{MATERIAL PROPERTIES IN ANSYS}

7.1.1 Reinforced Concrete :An eight-node solid element, Solid65, was used to model the concrete. The solid element has eight nodes with three degrees of freedom at each node - translations in the nodal $\mathrm{x}, \mathrm{y}$, and $\mathrm{z}$ directions. The element is capable of plastic deformation, cracking in three orthogonal directions, and crushing. A Link8 element is used to model the steel reinforcement. Two nodes are required for this element. Each node has three degrees of freedom, - translations in the nodal $\mathrm{x}, \mathrm{y}$, and $\mathrm{z}$ directions. The element is also capable of plastic deformation. The geometry and node locations for this element type are shown in Figure below.

7.1.2 Concrete :Development of a model for the behavior of concrete is a challenging task. Concrete is a quasibrittle material and has different behavior in compression and tension. The tensile strength of concrete is typically $8-15 \%$ of the compressive strength (Shah, et al. 1995). Figure below shows a typical stress-strain curve for normal weight concrete (Bangash 1989).In compression, the stress-strain curve for concrete is linearly elastic up to about 30 percent of the maximum compressive strength. Above this point, the stress increases gradually up to the maximum compressive strength. After it reaches the maximum compressive strength $\sigma_{\mathrm{cu}}$, the curve descends into a softening region, and eventually crushing failure occurs at an ultimate strain $\varepsilon_{\text {cu }}$. In 
tension, the stress-strain curve for concrete is approximately linearly elastic up to the maximum tensile strength. After this point, the concrete cracks and the strength decreases gradually to zero (Bangash 1989).

7.1.3 Steel Reinforced Concrete [Smeared Model] Material Properties: In this project the structure has been modeled using Steel Reinforced Concrete. The material properties mentioned below act equivalent for a Smeared Reinforcement concrete model using solid 65 element in Ansys. Many research papers have been published using similar kind of model. Broujerdian et. al (2010) have worked using a similar approach. The used of this features enables obtaining good results with less solver and modeling time.

7.1. 4 Loading The beam load was applied to the model. The load of $5 \mathrm{KN}$ was applied at the tip of the beam end with 6 load steps.

7.1.5 Load cases Different type of load cases are already inbuilt in Ansys Software they are supports, prescribed deformation, forces, temperature, shrinkage and prestressing.

7.1.6 Maximum Iteration limit A maximum iteration limit of 30 was used with all of the models. This generally proved sufficient to exceed the failure criterion.
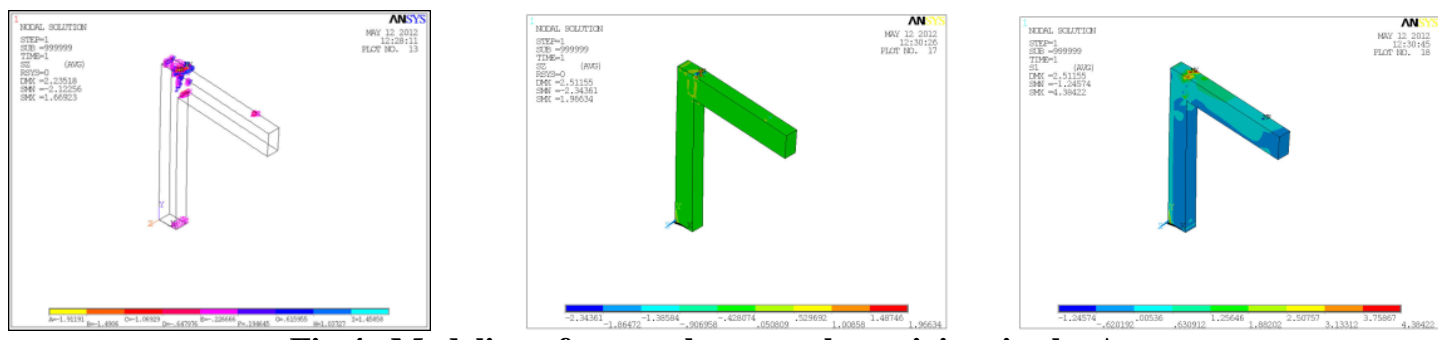

Fig.4 Modeling of corner beam column joints in the Ansys.
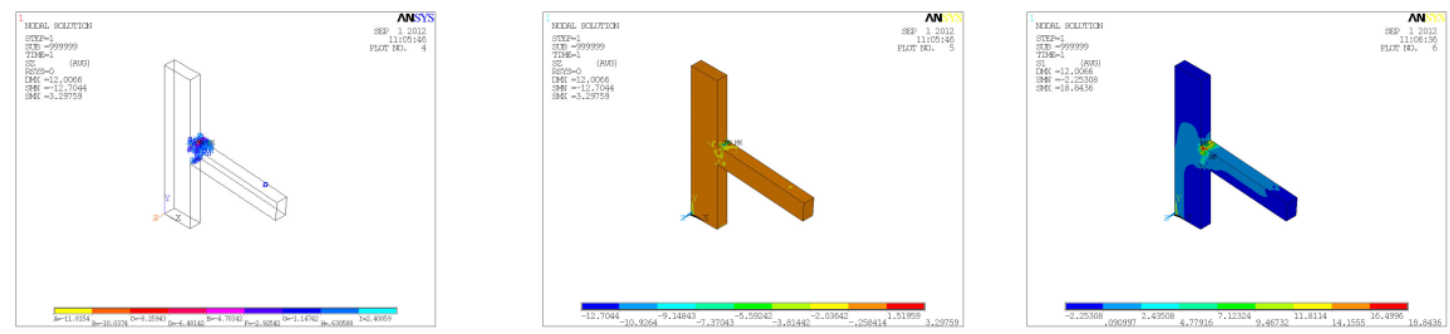

Fig.5 Modeling of Exterior beam column joints in the Ansys.

\section{Results and Discussions}

8.1 Parametric Study:-The exterior and corner beam-column joints are studied with different parameters like i.e. Maximum principle stress, Minimum principle stress, Displacement, Deformation, Stiffness variation of beam column joint i.e. Corner and Exterior joint subjected to monotonic loading.

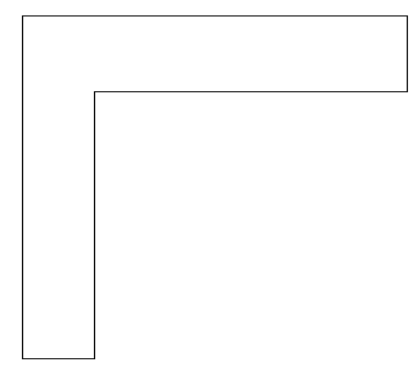

Fig.6 Case No.(1) Corner Beam-column Joint.

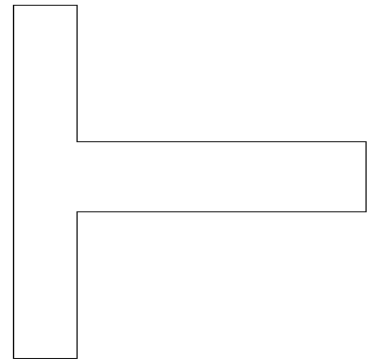

Fig.7 Case No.(2) Exterior Beam-column Joint. 
1. Corner beam column joint

Beam size

$230 \mathrm{~mm}$ X $350 \mathrm{~mm}$

Column size

$230 \mathrm{~mm} \times 700 \mathrm{~mm}$

Table I

\begin{tabular}{|c|c|c|c|}
\hline $\begin{array}{c}\text { Load } \\
\text { in } \\
\text { KN }\end{array}$ & $\begin{array}{l}\text { Displacement } \\
\text { in } \mathbf{~ m m}\end{array}$ & $\begin{array}{l}\text { Mini. } \\
\text { Stress } \\
\text { in } \\
\mathbf{N} / \mathbf{m m}^{2}\end{array}$ & $\begin{array}{c}\text { Maxi. } \\
\text { Stress } \\
\text { in } \\
\mathbf{N} / \mathbf{m m}^{2}\end{array}$ \\
\hline 5 & 0.8139 & $\begin{array}{c}- \\
0.6090\end{array}$ & 0.8418 \\
\hline 10 & 1.6000 & -8.099 & 8.800 \\
\hline 15 & 1.8000 & -8.809 & 8.900 \\
\hline 20 & 2.2000 & $\begin{array}{c}- \\
10.158\end{array}$ & 8.500 \\
\hline 25 & 3.0000 & $\begin{array}{c}- \\
12.500\end{array}$ & 9.500 \\
\hline 30 & 4.05 & - & 10.975 \\
\hline
\end{tabular}

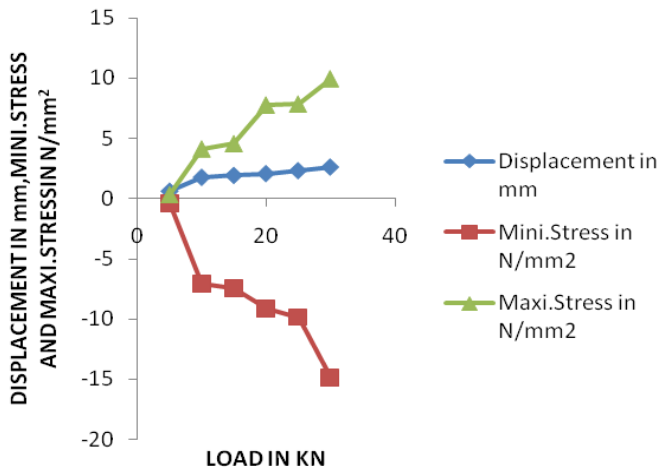

Fig.8 LOAD VS MAXIMUM DEFORMATION, MINIMUM STRESS, MAXIMUM STRESS GRAPH FOR CORNER BEAM COLUMN JOINT

2. Exterior beam column joint

$\begin{array}{ll}\text { Beam } & 230 \mathrm{mmx} \text { 350mm } \\ \text { Column } & 230 \mathrm{mmx} 700 \mathrm{~mm}\end{array}$

Table II

\begin{tabular}{|c|c|c|c|}
\hline $\begin{array}{l}\text { Load in } \\
\text { KN }\end{array}$ & $\begin{array}{l}\text { Displacement in } \\
\text { mm }\end{array}$ & $\begin{array}{l}\text { Mini. Stress } \\
\text { in N/mm }\end{array}$ & $\begin{array}{l}\text { Maxi. } \\
\text { Stress } \\
\text { in N/mm }\end{array}$ \\
\hline 5 & 0.9923 & -0.8959 & 0.83653 \\
\hline 10 & 1.9530 & -4.8873 & 6.60322 \\
\hline 15 & 2.3000 & -6.9834 & 7.82132 \\
\hline 20 & 2.2200 & -11.936 & 11.6000 \\
\hline 25 & 2.4835 & -14.996 & 15.4050 \\
\hline 30 & 2.6580 & -17.986 & 19.6000 \\
\hline
\end{tabular}

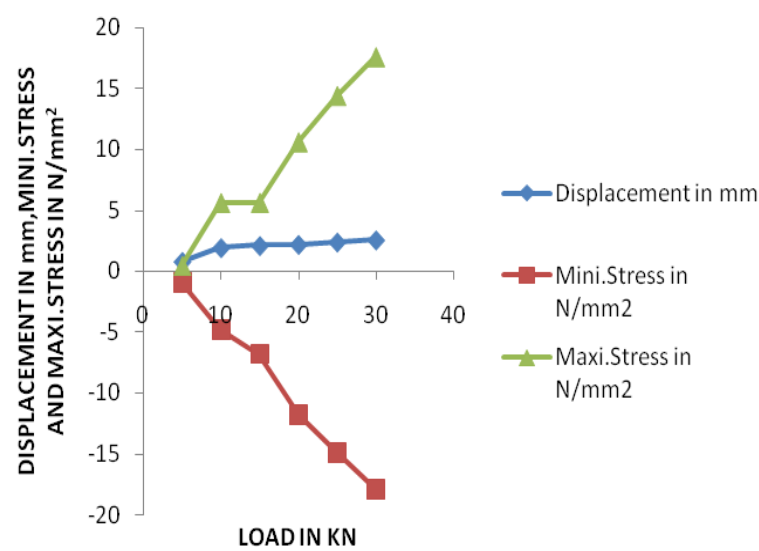

Fig.9 LOAD VS MAXIMUMDEFORMATION, MINIMUM STRESS,MAXIMUM STRESS GRAPH FOR EXTERIOR BEAM COLUMN JOINT 
3. Corner beam column joint with varying stiffness Table III

\begin{tabular}{|l|l|l|l|}
\hline $\begin{array}{l}\text { Load } \\
\text { in } \\
\mathbf{K N}\end{array}$ & $\begin{array}{l}\text { Displacement } \\
\text { in } \mathbf{~ m m}\end{array}$ & $\begin{array}{l}\text { Mini. Stress } \\
\text { In N/mm }^{2}\end{array}$ & $\begin{array}{l}\text { Maxi. } \\
\text { Stress } \\
\text { in } \\
\mathbf{N} / \mathbf{m m}^{2}\end{array}$ \\
\hline 5 & 0.80605 & & 1.6168 \\
\hline & & & \\
& & & \\
10 & 1.50809 & -1.92825 & 2.3332 \\
\hline 15 & 2.8850 & -2.66995 & 4.8430 \\
\hline 20 & 2.9060 & -3.60960 & 6.6852 \\
\hline 25 & 3.8050 & -3.98935 & 8.5089 \\
\hline 30 & 4.5080 & -5.60905 & 10.856 \\
\hline
\end{tabular}

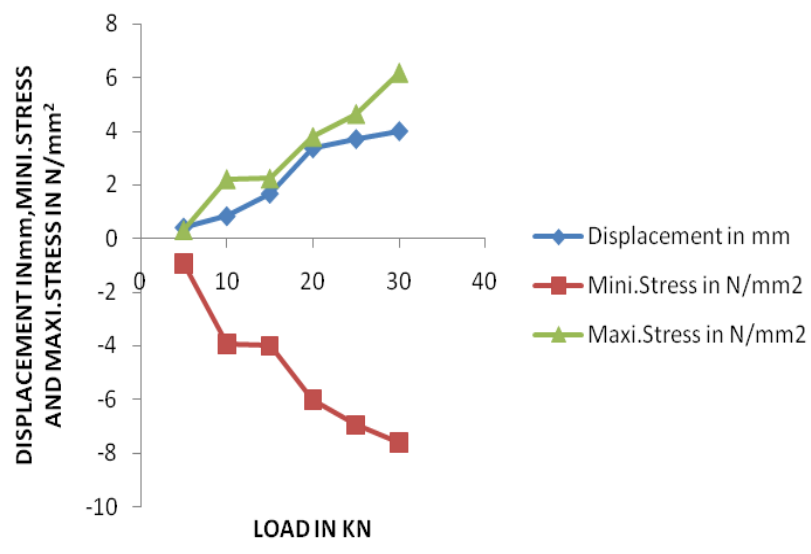

Fig.10 LOAD VS MAXIMUM DEFORMATION, MINIMUM STRESS, MAXIMUM STRESS GRAPH FOR CORNER BEAM COLUMN JOINT WITH VARYING STIFFNESS

\section{Case NO 1}

Beam $230 \mathrm{~mm} \mathrm{X} 450 \mathrm{~mm}$

Column $230 \mathrm{~mm} \mathrm{X} 900 \mathrm{~mm}$

Stiffness of beam : $\mathrm{K}_{\mathrm{B}}=282685.54 \mathrm{~mm}^{3}$

Stiffness of Column : $\mathrm{Kc}=2380000 \mathrm{~mm}^{3}$

Stiffness of Joint: $\mathrm{Kj}=\mathrm{K}_{\mathrm{B}} / \mathrm{Kc}$

$$
\begin{aligned}
& =282685.54 / 2380000 \\
& =0.11
\end{aligned}
$$

\begin{tabular}{|c|c|c|c|}
\hline $\begin{array}{c}\text { Load } \\
\text { in KN }\end{array}$ & $\begin{array}{c}\text { Displacement } \\
\text { in mm }\end{array}$ & $\begin{array}{c}\text { Mini. Stress } \\
\text { in N/mm }\end{array}$ & $\begin{array}{c}\text { Maxi. } \\
\text { Stress } \\
\text { in N/mm }\end{array}$ \\
\hline 5 & 0.6172 & -0.8314 & 0.6034 \\
\hline 10 & 0.9344 & -4.9641 & 2.5058 \\
\hline 15 & 2.3689 & -5.6780 & 3.3358 \\
\hline 20 & 4.4478 & -6.7839 & 4.8844 \\
\hline 25 & 5.6989 & -7.9569 & 5.7425 \\
\hline 30 & 7.9736 & -8.5050 & 6.8811 \\
\hline
\end{tabular}

Table IV 


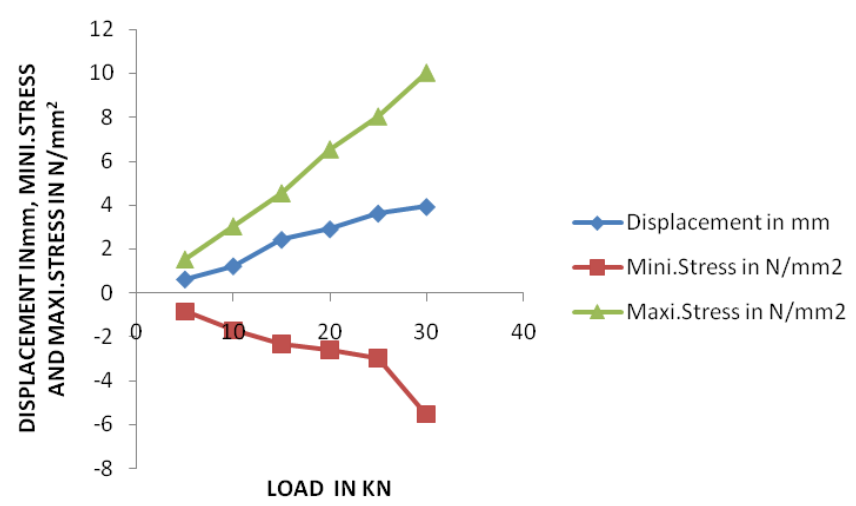

Fig.11 LOAD VS MAXIMUM DEFORMATION, MINIMUM STRESS, MAXIMUM STRESS GRAPH FOR CORNER BEAM COLUMN JOINT

\section{Case NO 2}

$\begin{array}{ll}\text { Beam } & 230 \mathrm{~mm} \times 600 \mathrm{~mm} \\ \text { Column } & 230 \mathrm{~mm} \times 600 \mathrm{~mm}\end{array}$

Column $230 \mathrm{~mm} \times 600 \mathrm{~mm}$

Stiffness of beam : $\mathrm{K}_{\mathrm{B}}=436640.62 \mathrm{~mm}^{3}$

Stiffness of Column : Kc $=436640.62 \mathrm{~mm}^{3}$

Stiffness of Joint: $\mathrm{Kj}=\mathrm{K}_{\mathrm{B}} / \mathrm{Kc}$

$$
\begin{aligned}
& =436640.62 / 436640.62 \\
& =1.00
\end{aligned}
$$

\section{Exterior beam column joint with varying stiffness}

Case NO 1

$\begin{array}{ll}\text { Beam } & 230 \mathrm{~mm} \mathrm{X} 450 \mathrm{~mm} \\ \text { Column } & 230 \mathrm{~mm} \mathrm{X} 900 \mathrm{~mm}\end{array}$

Stiffness of beam : $\mathrm{K}_{\mathrm{B}}=282685.54 \mathrm{~mm}^{3}$

Stiffness of Column : Kc $=2380000 \mathrm{~mm}^{3}$

Stiffness of Joint: $\mathrm{Kj}=\mathrm{K}_{\mathrm{B}} / \mathrm{Kc}$

$$
=282685.54 / 2380000
$$

\begin{tabular}{|c|c|c|c|}
\hline $\begin{array}{c}\text { Load } \\
\text { in } \\
\text { KN }\end{array}$ & $\begin{array}{l}\text { Displacement in } \\
\text { mm }\end{array}$ & $\begin{array}{l}\text { Mini. Stress } \\
\text { In N/mm }\end{array}$ & $\begin{array}{c}\text { Maxi. Stress } \\
\text { in } \mathbf{N} / \mathbf{m m}^{2}\end{array}$ \\
\hline 5 & 0.80465 & -0.88952 & 1.7288 \\
\hline 10 & 1.60958 & -1.92850 & 3.5080 \\
\hline 15 & 3.48646 & -2.66885 & 5.5690 \\
\hline 20 & 3.90996 & -2.80958 & 7.6085 \\
\hline 25 & 4.65950 & -2.99665 & 9.0580 \\
\hline 30 & 5.80859 & -5.95655 & 10.5090 \\
\hline
\end{tabular}

$$
=0.11
$$

Table IV 


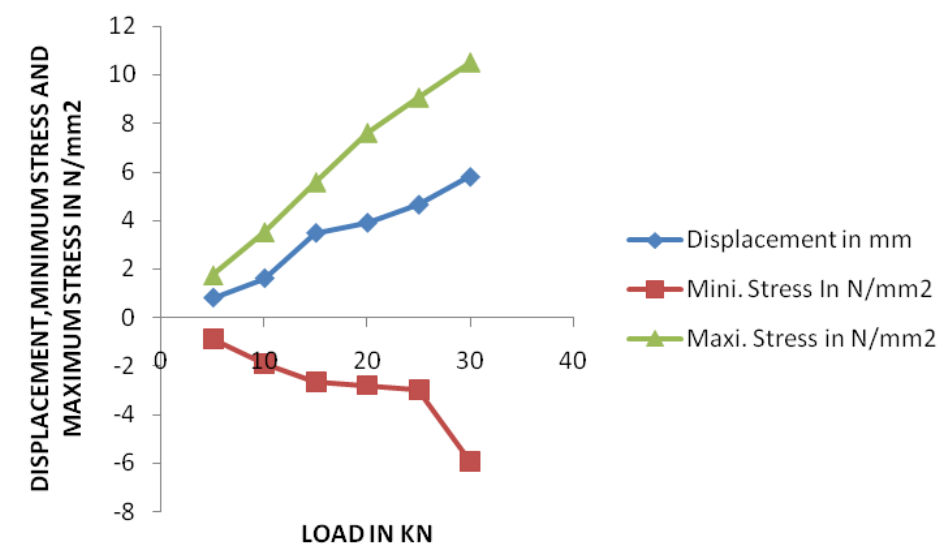

Fig.12 LOAD VS MAXIMUM DEFORMATION, MINIMUM STRESS, MAXIMUM STRESS GRAPH FOR EXTERIOR BEAM COLUMN JOINT

\section{Case NO 2}

$\begin{array}{ll}\text { Beam } & 230 \mathrm{~mm} \times 600 \mathrm{~mm} \\ \text { Column } & 230 \mathrm{~mm} \times 600 \mathrm{~mm}\end{array}$

Stiffness of beam : $\mathrm{K}_{\mathrm{B}}=436640.62 \mathrm{~mm}^{3}$

Stiffness of Column : Kc $=436640.62 \mathrm{~mm}^{3}$

Stiffness of Joint: $\mathrm{Kj}=\mathrm{K}_{\mathrm{B}} / \mathrm{Kc}$

$$
\begin{aligned}
& =436640.62 / 436640.62 \\
& =1.00
\end{aligned}
$$

\begin{tabular}{|}
\begin{tabular}{|c|c|c|c|}
\hline $\begin{array}{c}\text { Load } \\
\text { in } \\
\text { KN }\end{array}$ & $\begin{array}{c}\text { Displacement in } \\
\mathbf{~ m m}\end{array}$ & $\begin{array}{c}\text { Mini. Stress } \\
\text { In N/mm }\end{array}$ & $\begin{array}{c}\text { Maxi. Stress } \\
\text { in N/mm }\end{array}$ \\
\hline 5 & 0.204060 & -0.628264 & 1.885095 \\
\hline 10 & 0.405070 & -0.965852 & 2.807054 \\
\hline 15 & 0.697950 & -1.489700 & 3.889520 \\
\hline 20 & 1.905080 & -1.870850 & 7.908050 \\
\hline 25 & 2.204088 & -2.225578 & 8.608055 \\
\hline 30 & 2.805689 & -2.956850 & 10.55660 \\
\hline
\end{tabular}
\end{tabular}

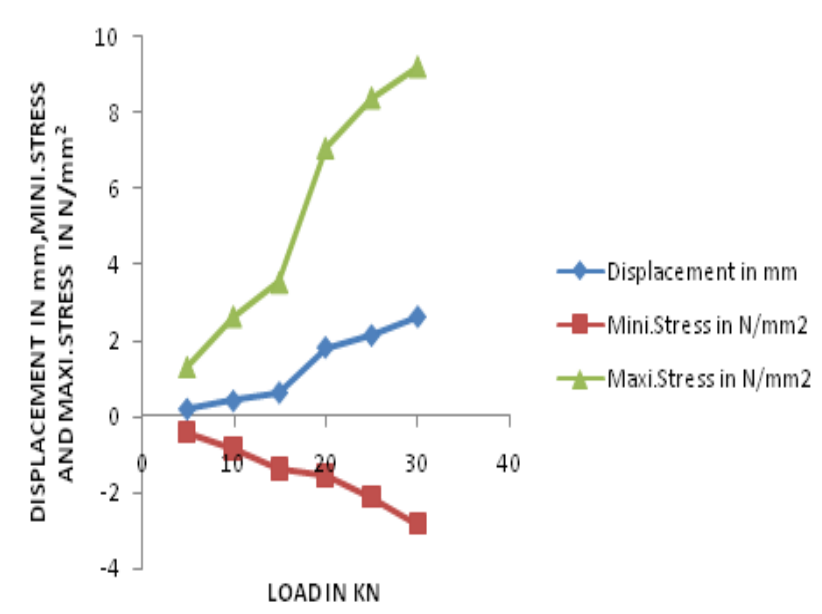

Fig.12 LOAD VS MAXIMUM DEFORMATION, MINIMUM STRESS,MAXIMUM STRESS GRAPH FOR EXTERIOR BEAM COLUMN JOINT 
7. Variation in stiffness of corner beam column joint Table VI

\begin{tabular}{|c|c|c|}
\hline $\begin{array}{c}\text { Load } \\
\text { in } \\
\mathbf{K N}\end{array}$ & $\begin{array}{c}\text { Displacement in } \\
\mathbf{m m}\end{array}$ & $\begin{array}{c}\text { Displacement in } \\
\mathbf{~ m m}\end{array}$ \\
\hline & $\mathbf{S j = 0 . 1 1}$ & $\mathbf{S j}=\mathbf{1 . 0 0}$ \\
\hline 5 & 0.6172 & 0.80605 \\
\hline 10 & 0.9344 & 1.50809 \\
\hline 15 & 2.3689 & 2.8850 \\
\hline 20 & 4.4478 & 2.9060 \\
\hline 25 & 5.6989 & 3.8050 \\
\hline 30 & 7.9736 & 4.5080 \\
\hline
\end{tabular}

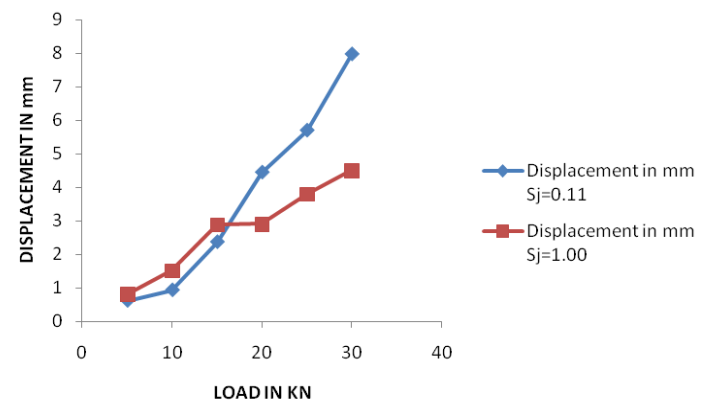

Fig.13 LOAD VS DISPLACEMENT GRAPH FOR CORNER BEAM COLUMN JOINT ( VARIATION IN STIFFNESS )

8. Variation in stiffness of corner beam column joint Table.VII

\begin{tabular}{|c|c|c|}
\hline $\begin{array}{c}\text { Load } \\
\text { in KN }\end{array}$ & $\begin{array}{c}\text { Mini. Stress in } \\
\mathbf{N} / \mathbf{m m}^{2}\end{array}$ & $\begin{array}{c}\text { Mini. Stress in } \\
\mathbf{N} / \mathbf{m m}^{2}\end{array}$ \\
\hline & $\mathbf{S j = 0 . 1 1}$ & $\mathbf{S j}=\mathbf{1 . 0 0}$ \\
\hline 5 & -0.8314 & -0.86965 \\
\hline 10 & -4.9641 & -1.92825 \\
\hline 15 & -5.6780 & -2.66995 \\
\hline 20 & -6.7839 & -3.60960 \\
\hline 25 & -7.9569 & -3.98935 \\
\hline 30 & -8.5050 & -5.60905 \\
\hline
\end{tabular}
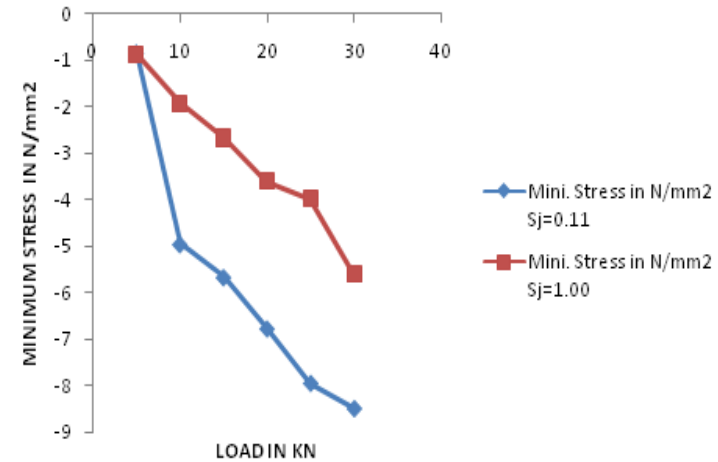

Fig. 14 LOAD VS MINIMUM STRESS GRAPH FOR CORNER BEAM COLUMN JOINT( VARIATION IN STIFFNESS )

9. Variation in stiffness of corner beam column joint Table VIII

\begin{tabular}{|c|c|c|}
\hline $\begin{array}{c}\text { Load } \\
\text { in KN }\end{array}$ & $\begin{array}{c}\text { Maxi. Stress } \\
\text { in } \mathbf{N} / \mathbf{m m}^{\mathbf{2}}\end{array}$ & $\begin{array}{c}\text { Maxi. Stress } \\
\text { in } \mathbf{~ N} \mathbf{m m}^{\mathbf{2}}\end{array}$ \\
\hline & $\mathbf{S j = 0 . 1 1}$ & $\mathbf{S j}=\mathbf{1 . 0 0}$ \\
\hline 5 & 0.6034 & 1.6168 \\
\hline 10 & 2.5058 & 2.3332 \\
\hline 15 & 3.3358 & 4.8430 \\
\hline 20 & 4.8844 & 6.6852 \\
\hline 25 & 5.7425 & 8.5089 \\
\hline 30 & 6.8811 & 10.856 \\
\hline
\end{tabular}

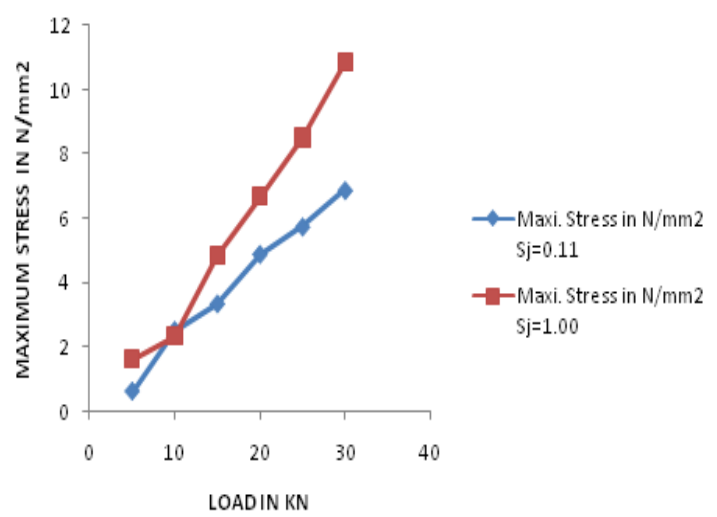

Fig. 15 LOAD VS MAXIMUM STRESS GRAPH FOR CORNER BEAM COLUMN JOINT (VARIATION IN STIFFNESS) 
10. Variation in stiffness of Exterior beam column joint:

\begin{tabular}{|c|c|c|}
\hline $\begin{array}{c}\text { Load } \\
\text { in KN }\end{array}$ & $\begin{array}{c}\text { Displacement in } \\
\text { mm }\end{array}$ & $\begin{array}{c}\text { Displacement } \\
\text { in } \mathbf{~ m m}\end{array}$ \\
\hline & $\mathbf{S j = 0 . 1 1}$ & $\mathbf{S j}=\mathbf{1 . 0 0}$ \\
\hline 5 & 0.80465 & 0.204060 \\
\hline 10 & 1.60958 & 0.405070 \\
\hline 15 & 3.48646 & 0.697950 \\
\hline 20 & 3.90996 & 1.905080 \\
\hline 25 & 4.65950 & 2.204088 \\
\hline 30 & 5.80859 & 2.805689 \\
\hline
\end{tabular}

Table IX

Fig.16 LOAD VS DISPLACEMENT GRAPH FOR EXTERIOR BEAM COLUMN JOINT (VARIATION IN STIFFNESS)

11. Variation in stiffness of Exterior beam column joint:-

TABLE X

\begin{tabular}{|c|c|c|}
\hline $\begin{array}{l}\text { Load } \\
\text { in } \\
\text { KN }\end{array}$ & $\begin{array}{l}\text { Mini. Stress in } \\
\mathbf{N} / \mathbf{m m}^{2}\end{array}$ & $\begin{array}{l}\text { Mini. Stress in } \\
\mathbf{N} / \mathbf{m m}^{2}\end{array}$ \\
\hline & $\mathbf{S j}=\mathbf{0 . 1 1}$ & $\mathbf{S j}=\mathbf{1 . 0 0}$ \\
\hline 5 & -0.88952 & -0.628264 \\
\hline 10 & -1.92850 & -0.965852 \\
\hline 15 & -2.66885 & -1.489700 \\
\hline 20 & -2.80958 & -1.870850 \\
\hline 25 & -2.99665 & -2.225578 \\
\hline 30 & -5.95655 & -2.956850 \\
\hline
\end{tabular}
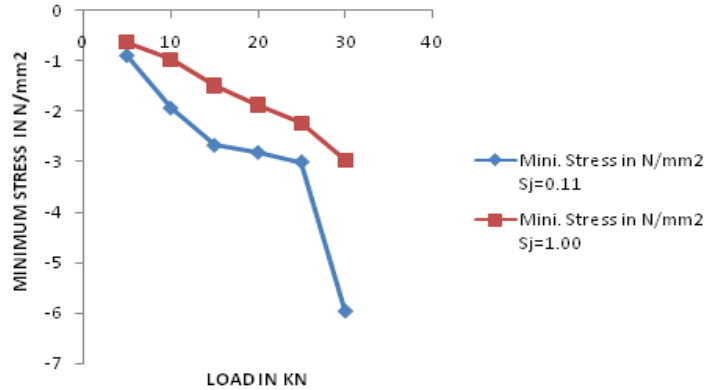

Fig.17 LOAD VS MINIMUM STRESS GRAPH FOR EXTERIOR BEAM COLUMN JOINT (VARIATION IN STIFFNESS)

12. Variation in stiffness of Exterior beam column joint:

Table XI

\begin{tabular}{|c|c|c|}
\hline $\begin{array}{l}\text { Load in } \\
\text { KN }\end{array}$ & $\begin{array}{c}\text { Maxi. Stress in } \\
\mathbf{N} / \mathbf{m m}^{2}\end{array}$ & $\begin{array}{c}\text { Maxi. Stress in } \\
\mathbf{N} / \mathbf{m m}^{2}\end{array}$ \\
\hline & $\mathbf{S j = 0 . 1 1}$ & $\mathbf{S j = 1 . 0 0}$ \\
\hline 5 & 1.7288 & 1.885095 \\
\hline 10 & 3.5080 & 2.807054 \\
\hline 15 & 5.5690 & 3.889520 \\
\hline 20 & 7.6085 & 7.908050 \\
\hline 25 & 9.0580 & 8.608055 \\
\hline 30 & 10.5090 & 10.55660 \\
\hline
\end{tabular}

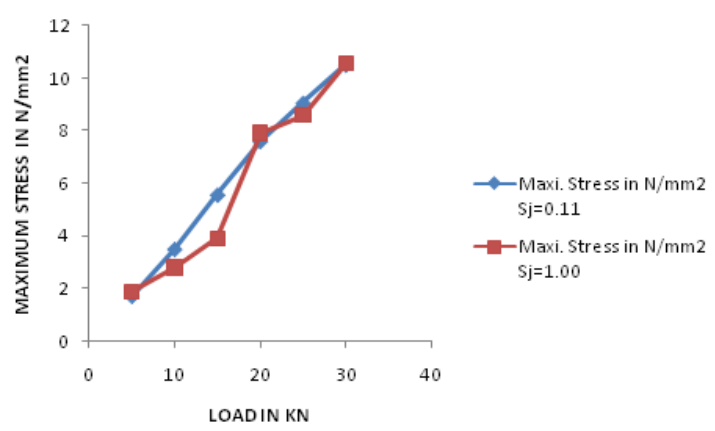

FOR EXTERIOR BEAM COLUMN JOINT (VARIATION IN STIFFNESS)

\section{IX.CONCLUSION}

1) As load increases displacement, minimum stress and maximum stress also increases.

2) For stiffness variation of corner joint for $\mathrm{Kj}=0.11$ the displacement is minimum as compare to $\mathrm{Kj}=1$.

3) For stiffness variation of corner joint for $\mathrm{Kj}=0.11$ the minimum stress is more as compare to $\mathrm{Kj}=1$.

4) For stiffness variation of corner joint for $\mathrm{Kj}=0.11$ the maximum stress is more as compare to $\mathrm{Kj}=1$.

5) For stiffness variation of Exterior joint for $\mathrm{Kj}=0.11$ the displacement is minimum as compare to $\mathrm{Kj}=1$.

6) For stiffness variation of Exterior joint for $\mathrm{Kj}=0.11$ the minimum stress is more as compare to $\mathrm{Kj}=1$.

7) For stiffness variation of Exterior joint for $\mathrm{Kj}=0.11$ the maximum stress is less as compare to $\mathrm{Kj}=1$.

8) The behavior of corner beam column joint is different than that of the exterior beam column joint.

9) As stiffness of the structure changes the displacement, minimum stress and maximum stress changes w. $r$ t .loading. 
10) Here the behavior of exterior and corner beam-column joint is studied one can also go for interior joint with Ansys.

11) One can also try beam-column joint retrofitted with carbon fiber reinforced polymer sheets ( CFRP) to study the

Behavior of beam-column joint subjected to monotonic loading.

12) One can also go for experimental model of beam-column joint i.e. corner and exterior beam-column jointin laboratory and apply monotonic loading to the models at the free end of beam.

13) One can also study different loading conditions on beam-column joint. i. e. cyclic loading, random loading etc.

14) The behavior of joint can also be studied by applying column axial load to the Joint in Ansys. Where $\mathrm{Kj}=$ beam column joint stiffness ratio/ Factor

\section{Journal Papers:}

\section{References}

[1] Hwang Shyh-Jiann and Lee Hung-Jen Analytical Model for Predicting Shear Strengths of Exterior Reinforced Concrete Beam-Column Joints for Seismic Resistance ACI Structural Journal, September-October 2005, Vol. 96, No.5.

[2] H. F. Wong and J. S. Kuang Effect of Beam-Column depth ratio on design on joint seismic Proceedings of Institution of Civil Engineers Structures and Buildings,2008, 91-101.

[3] Jaehong kim and James .M. Lafave Key influence parameters for the Joint shear behavior of RC beam-column Connections Engineering Structures, 2007, 2523-2539.

[4] Bing Li, Yiming Wu, and Tso-Chien Pan. Seismic Behavior of Non seismically Detailed Interior Beam-Wide Column Joints-Part II: Theoretical Comparisons and Analytical Studies. ACI Structural Journal, January-February 2003, V.100, No.1.

[5] Lowes.N.Laira, Mitra Nilanjan and Altoontash Arash A beam-column Joint model for simulating the earthquake response of Reinforced Concrete Frames. Pacific Earthquake Engineering Research Center (PEER), 2004,1-66.

[6] Murty.C.V.R, Rai.C.Durgesh, Bajpai.K.K and Jain.S.K Anchorage detail and joint design in seismic RC Frames. The Indian Concrete Journal, April 2001 , 274-280.

[7] Pampanin.S., Calvi.G.M. and Morati.M. Seismic Behavior of Reinforced Concrete Beam-Column Joints designed for GrLoads 12th European Conference on Earthquake Engineering, 1998,1 -10.

[8] Hegger Josef, Sherif Alaa and Roeser Wolfgang Nonlinear Finite Element Analysis of Reinforced Concrete Beam-ColConnections ACI Structural Journal, Sept-Oct 2004, 604-614.

[9] R. Vollum and D. Parker External beam-column joints design to Eurocode2 Magazine of Concrete Research,2008, 511-521.

[10] Shamim Mohammad and Kumar. V Behavior of reinforced concrete Beam column joints-A review Journal of StruEngineering Vol.26, No.3, 1999, 207-214.

[11] Shin.S.W., Lee.S.K. AND Ghosh.S.K. High Strength concrete beam- Column joints Proceedings of the Tenth World Conferenon Earthquake Engineering ,1992,3145-3149.

[12] Ha.J.G. and Cho.C.G. Strengthening of Reinforced high-strength concrete b-c joints using advanced reinforcement detailMagazine of Concrete Research, 2008, 487-497.

[13] J. S. Kuang and H. F. Wong Effects of beam bar anchorage on beam-column Joint behavior Proceedings of the Institution of Civil Engineers Structures and Buildings, 2006,115-124.

[14] Laura N. Lowes1 and Arash Altoontash Modeling Reinforced-Concrete Beam-Column Joints Subjected to Cyclic Loading Journal of Structural Engineering ,2003, 1686-1697.

\section{Acknowledgements}

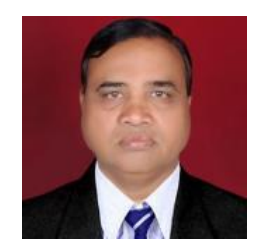

B.E. (Civil), M.E. (Civil - Structures) , PhD., L.M. (ISSE)

Prof. Patil S. S..

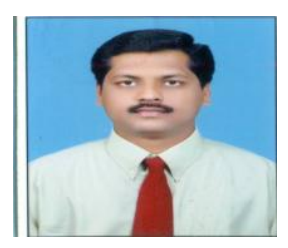

B.E. (Civil), M.E. (Civil - Structures) ,L.M. (ISSE),

Prof. Konapure. C. G.

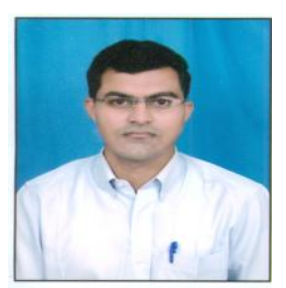

B.E. (Civil), M.E. (Civil - Structures), L.M. (ISSE),

Mr. Manekari S. S. 